\title{
Aa. Vv, Francesistica: bibliografia delle opere e degli studi di letteratura francese e francofona in Italia
} 1995-1999

\section{Emanuele Kanceff}

\section{(2) OpenEdition \\ Journals}

\section{Edizione digitale}

URL: https://journals.openedition.org/studifrancesi/41088

DOI: $10.4000 /$ studifrancesi. 41088

ISSN: 2421-5856

\section{Editore}

Rosenberg \& Sellier

\section{Edizione cartacea}

Data di pubblicazione: 1 juillet 2004

Paginazione: $217-218$

ISSN: 0039-2944

\section{Notizia bibliografica digitale}

Emanuele Kanceff, «Aa. VV, Francesistica: bibliografia delle opere e degli studi di letteratura francese e francofona in Italia 1995-1999», Studi Francesi [Online], 142 (XLVIII | I) | 2004, online dal 30 novembre 2015, consultato il 09 septembre 2021. URL: http://journals.openedition.org/studifrancesi/41088; DOI: https://doi.org/10.4000/studifrancesi.41088

Questo documento è stato generato automaticamente il 9 septembre 2021.

\section{cc) $($ ) $\ominus$}

Studi Francesi è distribuita con Licenza Creative Commons Attribuzione - Non commerciale - Non opere derivate 4.0 Internazionale. 


\title{
Aa. Vv, Francesistica: bibliografia delle opere e degli studi di letteratura francese e francofona in Italia 1995-1999
}

\author{
Emanuele Kanceff
}

\section{NOTIZIA}

AA. VV., SOCIETÀ UNIVERSITARIA PER GLI STUDI DI LINGUA E LETTERATURA FRANCESE, Francesistica: bibliografia delle opere e degli studi di letteratura francese e francofona in Italia 1995-1999, III, a cura di Graziano BENELLI, Giovanni BogLIOLO, Paolo CARILE, Giorgetto GIORGI, Mario MATUCCI, Benedetta PAPASOGLI, Torino, L'Harmattan Italia, 2001, pp. 774.

1 Nonostante quest'opera non competa alla sezione Novecento, credo che ci sarà consentito spendere una parola a proposito dell'ottima sezione Novecento, a cura di Valeria POMPEJANO e Angela CIANCIMINO, sezione certamente non delle più facili da redigere, che mostra con le sue circa ottanta pagine la ricchezza e il fervore degli studi novecenteschi in Italia. 